View Article Online / Journal Homepage / Table of Contents for this issue

THE ACTION OF ACETYL CHLORIDE ON ACETOXIMES. 683

LXX.-The Action of Acetyl Chloride on Acetoximes.

By Victor Meyer, Ph.D., and Arther W. Warrington, B.Sc.

Investigations of the action of acetyl chloride on the aldoximes and acetoximes have yielded many interesting results. Most aldoximes, when treated with this reagent, yield nitriles, according to the general equation-

$$
\mathrm{RCH}: \mathrm{N} \cdot \mathrm{OH}=\mathrm{RC}: \mathrm{N}+\mathrm{H}_{2} \mathrm{O} \text {. }
$$

Most acetoximes, on the other hand, yield acetates of the general furmula-

$$
\mathrm{R}_{2} \mathrm{C}: \mathrm{N} \cdot \mathrm{O} \cdot \mathrm{C}_{3} \mathrm{H}_{3} \mathrm{O} \text {. }
$$

Westenberger has shown, howerer, that the aldoxime obtained from terephthalic aldehyde is an exception to this rule, for, on treatment with acetyl chloride, it yields a very stable aceto-derivative. Farther, 
camphoroxime was found by E. Nägeli (Ber., 17, 806) not to yield an acetate, as might have been expected, but, like most aldoximes, an anhydride, which H. Goldschmidt and Zürrer (Ber., 17, 2071) showed to be the nitrile of campholenic acid. The latter fact can only be explained by supposing that camphor, as an additive product of the benzene series, contains hydrogen-atoms which resemble those of the aldehydes and aldoximes in the particularly exposed positions which they occupy.

Now, the question suggested itself whether terephthalic aldoxime and camphoroxime are the only exceptions to the above rules, or whether other aldoximes and acetoximes behave in an analogous fashion.

F. Münchmeyer (Ber., 20,507), at the request of one of us, investigated the action of acetyl chloride on isophthalic aldoxime, and obtained not an acetate, as is the case with terephthalic aldoxime, but metadicyanobenzene; a difference in the behaviour of two such similar bodies which is at present quite inexplicable.

In order to obtain a compound analogous to camphoroxime, and yet having a known constitutional formula, we prepared diisopropyl acetoxime-

$$
\left(\mathrm{CH}_{3}\right)_{2} \mathrm{CH} \cdot \mathrm{C}(\mathrm{N} \cdot \mathrm{OH}) \cdot \mathrm{CH}\left(\mathrm{CH}_{3}\right)_{2} \text {. }
$$

This acetoxime contains two tertiary hydrogen-atoms, one on each side of the isonitroso-group. Richard Meyer has shown how readily tertiary hydrogen-atoms are attacked; and their position seems to us quite comparable with that of hydrogen-atoms added to the benzenering.

\section{Diisopropyl Acetoxime.}

Diisopropyl acetoxime was prepared in the following manner:25 grams of hydroxylamine hydrochloride and an excess of caustic potash were dissolved in a mixture of equal volumes of water and alcohol, and the solution poured into a flask containing $25 \mathrm{grams}$ of diisopropyl ketone (prepared by the distillation of calcium isobutyrate). The flask was then connected with a reflux condenser, placed in a water-bath, and the contents heated for eight hours. The alcohol was then evaporated, the residual liquid diluted with water, and the acetoxime extracted with ether. After drying, the ether was distilled off and the oil remaining behind was purified by distillation.

$$
\left[\left(\mathrm{CH}_{3}\right)_{2} \mathrm{CH}\right]_{2} \mathrm{CO}+\mathrm{H}_{2} \mathrm{~N} \cdot \mathrm{OH}=\left[\left(\mathrm{CH}_{3}\right)_{2} \mathrm{CH}\right]_{2} \mathrm{C}: \mathrm{N} \cdot \mathrm{OH}+\mathrm{H}_{2} \mathrm{O} \text {. }
$$

Obtained in this way, diisopropyl acetoxime is a colourless liquid, having a strong and characteristic odour. It boils between $181^{\circ}$ 
and $185^{\circ}$, crystallises in melting snow, and melts between $+6^{\circ}$ and $+8^{\circ}$.

0.1555 gram acetoxime gave 14.4 c.c. N. $t=18.5^{\circ} . \quad \mathrm{P}=748 \mathrm{~mm}$.

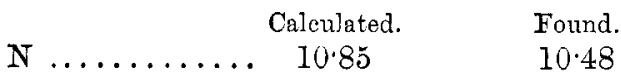

Action of Acetyl Chloride on Diisopropyl Acetoxime.

The action of acetyl chloride on diisopropyl acetoxime differs according as the temperature is kept low or allowed to rise. In the former case, part of the acetoxime is attacked and an acetate is formed; in the latter, a substance is obtained which, on treatment with water, yields a crystalline compound, isomeric with the acetoxime.

If the acetoxime is added cautiously, drop by drop, from a separating funnel, to a large excess of acetyl chloride, and, as soon as all the acetoxime has been added, the liquid is poured into a mixture of ice and water, an oil will rise to the surface, having a pleasant ethereal odour, and resembling that to be described in connection with dipropyl acetoxime.

If, however, instead of pouring the liquid into ice and water, the excess of acetyl chloride be driven off at $100^{\circ}$, and the residue heated for some time on the water-bath, the acetate is converted into a thick syrup, which is completely and readily soluble in water. When the aqueous solution of this substance is treated with an excess of strong canstic potash, an oil of an intense alkaloidal odour rises to the surface. The examination of this oil has yielded interesting and unexpected results. It has not a constant boiling point, and yet suffers but little decomposition on distillation. On standing, crystals separate from the oil; the separation of these crystals is favoured by spreading out the oil on large glass dishes. The whole mass seems to solidify, but on filtration a considerable quantity of the oily motherliquor is obtained. If the mother-liquor is again spread out more crystals separate. By repeating this operation, we succeeded in con. verting nearly all the oil into crystals; these were pressed between filter-paper, and crystallised out of lukewarm water.

To our astonishment, the pure crystals had not the faintest odour. The intense alkaloidal odour must be ascribed therefore not to the crystals, but to the oil, the last trace of which had only been removed by the recrystallisation.

The new compound possesses exceedingly interesting properties. It forms beautiful, colourless, transparent needles, which are very soluble in ether and alcohol, and quite soluble enough in water for 
the purpose of recrystallisation. It is very volatile; like naphthalene, it sublimes at the ordinary temperature of a room. It melts at $102^{\circ}$, and distils without the slightest decomposition at $210^{\circ}$.

Analysis gave the following results :-

I. 0.1587 gram substance gave $15 \cdot 2$ c.c. N. $t=21^{\circ}$ C. $\mathrm{P}=$ $742.5 \mathrm{~mm}$.

II. $0 \cdot 1344$ gram substance gave $12 \cdot 2$ c.c. $N . t=17^{\circ}$ C. $P=$ $754.5 \mathrm{~mm}$.

III. 0.2186 gram substance gave 0.5198 gram $\mathrm{CO}_{2}$ and 0.2301 gram $\mathrm{H}_{2} \mathrm{O}$.

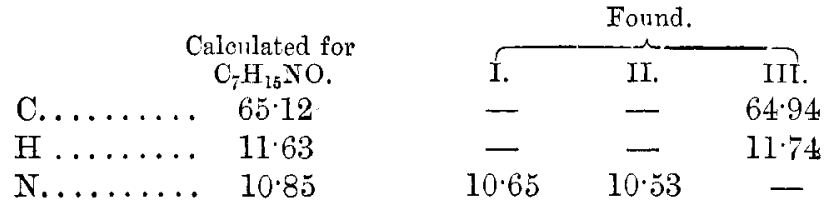

These numbers show that the new substance and the acetoxime used in its preparation, although their properties are so different, have, nevertheless, the same percentage composition. The vapourdensity of the new compound as determined in thymol vapour by C. and V. Meyer's method, gave results showing that its molecular weight also is identical with that of the acetoxime.

I. 0.0464 gram sulstance displaced 8.8 c.c. air. $t=24.5^{\circ} . \quad \mathrm{P}=$ $741.3 \mathrm{~mm}$.

II. 0.508 gram substance displaced 9.8 c.c. air. $t=24.5^{\circ} . \quad P=$ $741 \cdot 3 \mathrm{~mm}$.

III. 0.0396 gram substance displaced 7.55 c.c. air. $t=245^{\circ} . \quad \mathrm{P}=$ $741.3 \mathrm{~mm}$.

\begin{tabular}{|c|c|c|}
\hline $\begin{array}{c}\text { Vapour-density } \\
\text { calculated for } \mathrm{C}_{7} \mathrm{H}_{35} \mathrm{NO} \text {. }\end{array}$ & Var & $\begin{array}{l}\text { ur-density } \\
\text { found. }\end{array}$ \\
\hline & I.... & $4 \cdot 70$ \\
\hline $4 \cdot 47$ & II. . & $4 \cdot 62$ \\
\hline & III . . . . . . & $4 \cdot 67$ \\
\hline
\end{tabular}

What is the constitutional formula of the isomeride? It was thought that, as in the case of camphoroxime and of most aldoximes, the acetyl chloride had acted as a dehydrating agent, and that a compound having the following structural formula had at first been formed :-<smiles>CC(C)C1N=C1C(C)(C)C</smiles>

This wonld be a "metanitrile." But as metanitriles are very un- 
stable, it might be supposed that this hypothetical product recombined with water, and yielded-

$$
\left(\mathrm{CH}_{3}\right)_{2} \mathrm{CH} \cdot \mathrm{C}(\mathrm{NH}) \cdot \mathrm{C}\left(\mathrm{CH}_{3}\right)_{2} \cdot \mathrm{OH} \text {. }
$$

But the isomeride yielded no salts. Although it dissolved in acids, and on the addition of alkalis it readily separated out again, it did not yield any definite compound with hydrochloric acid, platinum tetrachloride, or sulphuric acid. An attempt was made to detect the presence of the imido-group by means of nitrous acid, but no nitroso. derivative could be obtained.

Its constitution was at last ascertained by a study of the products of its decomposition on continued boiling with concentrated alcoholic potash, or by heating it with concentrated hydrochloric acid in a closed tube, By either of these means it suffered decom. position, yielding only isobutyric acid and isopropylamine. After decomposition by hydrochloric acid, the isobutyric acid was driven over with steam, converted into the barium salt, and analysed.

0.3405 gram of the $\mathrm{Ba}$ salt dried at $150^{\circ} *$ yields 0.2574 gram $\mathrm{BaSO}_{4}$.

$$
\begin{array}{cc}
\text { Calculated for } \\
\left(\mathrm{C}_{4} \mathrm{H}_{7} \mathrm{O}_{2}\right)_{2} \mathrm{Ba} . & \text { Found. } \\
\mathrm{Ba} \ldots \ldots \ldots \quad 44.07 & 44.43
\end{array}
$$

A small portion of the calcium salt was prepared. It was more soluble in hot than in cold water, and must therefore have been a salt of isobutyric and not of butyric acid.

The isopropylamine was converted into the platinochloride, the analysis of which gave the following numbers:-

0.5988 gram platinochloride gave 0.2260 gram platinum after ignition.

$$
\begin{array}{cc}
\text { Calculated for } \\
\left(\left(\mathrm{CH}_{3}\right)_{2} \mathrm{CH} \cdot \mathrm{NH}_{2}\right)_{2}, \mathrm{H}_{2} \mathrm{P}_{\mathrm{tCl}} . & \text { Found. } \\
\text { Pt } \ldots \ldots \ldots & 37 \cdot 74
\end{array}
$$

This decomposition, taken together with the results obtained by Ernst Beckmann (Ber., 19, 992), in a recent investigation of the action of phosphorous pentachloride on diphenylacetosime, leaves scarcely a doubt as to its constitutional formula. Beckmann, by the action of phosphorous pentachloride on diphenylacetoxime, obtained a chloride, $\left(\mathrm{C}_{6} \mathrm{H}_{5}\right)_{4} \mathrm{CNCl}$, which on treatment with water yielded, not the original acetoxime as might have been expected,

* According to Fittig (Ber., 13, 1316), barium isobutyrate crystallises with $\frac{1}{2}$ mol. $\mathrm{H} . \mathrm{O}$, which it loses at $150^{\circ}$. 
but an isomeride. The chlorine had changed place with the phenyl group.

$$
\left(\mathrm{C}_{8} \mathrm{H}_{5}\right)_{2} \mathrm{C}: \mathrm{N} \cdot \mathrm{OH}+\mathrm{PCl}_{5}=\mathrm{C}_{6} \mathrm{H}_{5} \cdot \mathrm{CCl}: \mathrm{N} \cdot \mathrm{C}_{6} \mathrm{H}_{5}+\mathrm{HCl}+\mathrm{POCl}_{3} \text {. }
$$

This chloride Beckmann identifies beyond a doubt with one discovered by Wallach (Annalen, 184, 1). On treatment with water, it yielded benzanilide,

$$
\mathrm{C}_{6} \mathrm{H}_{5} \cdot \mathrm{CCl}: \mathrm{N} \cdot \mathrm{C}_{6} \mathrm{H}_{5}+\mathrm{HOH}=\mathrm{C}_{6} \mathrm{H}_{5} \cdot \mathrm{CO} \cdot \mathrm{NH} \cdot \mathrm{C}_{6} \mathrm{H}_{5}+\mathrm{HCl} \text {. }
$$

In a similar manner, in diisopropyl acetoxime, the chain of carbonatoms had been broken and relinked by nitrogen. Diisopropyl acetoxime had yielded

Isopropylamide of isobutyric acid, the compound we have been describing.

$$
\underset{\left(\mathrm{CH}_{3}\right)_{2} \mathrm{CH}}{\left(\mathrm{CH}_{3}\right)_{2} \mathrm{CH}}>\mathrm{C}: \mathrm{NOH} \text { yielded } \overline{\mathrm{d}} \underset{\left(\mathrm{CH}_{3}\right)_{2} \mathrm{CH} \cdot \mathrm{NH}}{\left(\mathrm{CH}_{3}\right)_{2} \mathrm{CH} \cdot \mathrm{CO}}<\frac{\mathrm{NH} \cdot \mathrm{CH} \cdot \mathrm{CH}\left(\mathrm{CH}_{3}\right)_{2}}{\left(\mathrm{CH}_{3}\right)_{2}}
$$

As we have shown, the ether,

$$
\left(\mathrm{CH}_{3}\right)_{2} \mathrm{CH} \cdot \mathrm{C}\left(\mathrm{N} \cdot \mathrm{O} \cdot \mathrm{C}_{2} \mathrm{H}_{3} \mathrm{O}\right) \cdot \mathrm{CH}\left(\mathrm{CH}_{3}\right)_{2},
$$

is at first formed, but what is the nature of the further reaction which takes place, resulting in the formation of isobutyryl-isopropylamine, we do not know.

If the above views concerning the constitution of the isomeride be correct, it should be easy to prepare it synthetically from isobutyryl chloride and isopropylamine. This we succeeded in doing.

T'he isobutyryl chloride necessary for this purpose was obtained from Kahlbaum, and the isopropylamine made by the reduction of ordinary acetoxime, according to the method lately published by H. Goldschmidt (Ber., 19, 3232).

An ethereal solution of isopropylamine combines with isobutyryl chloride to form a compound, which is identical with that obtained from diisopropylacetoxime in appearance, solubility, melting point, and chemical properties.

$$
\left(\mathrm{CH}_{3}\right)_{3} \mathrm{CH} \cdot \mathrm{COCl}+\mathrm{NH}_{2} \cdot \mathrm{CH}\left(\mathrm{CH}_{3}\right)_{2}=\underset{\left(\mathrm{CH}_{3}\right)_{3} \mathrm{CH} \cdot \mathrm{NH}}{\left(\mathrm{CH}_{3}\right)_{2} \mathrm{CH} \cdot \mathrm{CO}}>+\mathrm{HCl} .
$$

Thus the question of the constitution of this compound may be considered settled.

It has been observed that, besides the crystals of isobntyryl isopropylamine there was also an oil formed by the action of acetyl chloride on diisopropyl acetoxime; this oil possesses an intensely alkaloidal smell, and is possibly a derivative of pyridine. The nature of this oil will be the subject of further investigation. 


\section{Dipropyl Acetoxime.}

Dipropyl ketone, prepared by the distillation of calcium butyrate, was treated with hydroxylamine like the iso-compound.

The dipropyl acetoxime obtained was purified by distillation. It is a colourless liquid, boiling between $190^{\circ}$ and $195^{\circ}$, and it does not solidify in a freezing mixture.

0.2059 gram yielded 19.7 c.c. $\mathrm{N} . \quad t=15^{\circ} .5$ C. $P=746.3 \mathrm{~mm}$.

$\begin{array}{cr}\text { Calculated. } & \text { Found. } \\ \text { N . . } \quad 10.85 & 10.92\end{array}$

Action of Acetyl Chloride on Dipropyl Acetoxime.

In whatever way dipropyl acetoxime was treated with acetyl chloride, it always yielded an acetate. By allowing the acetoxime to drop into an excess of acetyl chloride, and boiling the mixture, in connection with a reflux condenser, all the acetoxime was converted into the acetate. After boiling, the mixture was poured into cold water. An oil of very pleasant odour rose to the surface; this was extracted with ether, the ether evaporated at about $50^{\circ}$, and the oil allowed to stand in a vacuum over sulphuric acid for several hours.

0.2720 gram gave 18.5 c.c. $\mathrm{N}$. $t=16^{\circ} . \mathrm{P}=752 \mathrm{~mm}$.

$$
\begin{gathered}
\text { Culculated for } \\
\mathrm{C} \quad \ldots \ldots \ldots \ldots \quad 8 \cdot 00
\end{gathered}
$$

In conclusion, it may be stated that it seems that a reaction similar to the one by which isobutyryl isopropylamine was obtained from diisopropyl acetoxime, only takes place when the acetoxime contains a tertiary hydrogen-atom.

Methylisopropyl acetoxime and phenylisopropyl acetoxime (Rattner, Ber., 20, 506),

$\left(\mathrm{CH}_{3}\right)_{2} \mathrm{CH} \cdot \mathrm{C}(\mathrm{NOH}) \cdot \mathrm{CH}_{3}$ and $\left(\mathrm{CH}_{3}\right)_{2} \mathrm{CH} \cdot \mathrm{C}(\mathrm{NOH}) \cdot \mathrm{C}_{6} \mathrm{H}_{5}$,

each containing a tertiary hydrogen-atom, behave like diisopropyl acetoxime when treated with acetyl chloride, while the acetoximes of benzophenone and acetophenone,

$$
\mathrm{C}_{6} \mathrm{H}_{5} \cdot \mathrm{C}(\mathrm{NOH}) \cdot \mathrm{C}_{6} \mathrm{H}_{5} \text { and } \mathrm{C}_{6} \mathrm{H}_{5} \cdot \mathrm{C}(\mathrm{NOH}) \cdot \mathrm{CH}_{3} \text {, }
$$

which do not contain tertiary hydrogen-atoms yield ethers when treated with acetyl chloride, as has been shown by E. Spiegler and Rattner respectively. 